\title{
Research and Application on low molecular weight polymer fracturing fluid system
}

\author{
Xiao Chao WANG ${ }^{a}$, Yuan Zhao JIA, Bin WANG, Peng WaNG, Zheng Dong XU, Gang Fei WU, Hui Juan LI \\ Huabei Oilfield Company Production Engineering Research Institute, $062552 \mathrm{He}$ bei ,China
}

\begin{abstract}
In order to reduce the secondary damage of melon gum fracturing fluid for the low permeability alkali sensitivity reservoir, Optimized a kind of low molecular weight polymer fracturing fluid, and solve the technical problem of crosslinking time is not easy to control, fracturing fluid gel breaking difficult in low temperature. Through the study of the optimization of main additives, The fracturing fluid use low molecular highly active three yuan low molecular polymer as a thickener, which use of special synthetic process of polymerization with multiple active node. Its molecular weight is $200000 \sim 300000$, water soluble speed is fast, site preparation easy, and thickening ability is strong. When the concentration is $0.2 \% \sim 0.6 \%$ in the fracturing fluid ,it can satisfy the requirement of fracturing operation. With organic zirconium and aldehyde compounds as crosslinking agent, The fracturing fluid have been achieved in good results in erlian uli of north China oilfield, ordos basin yishan slope of oil well and gas well fracturing.
\end{abstract}

Key words. Low permeability; Alkali sensitivity; Low molecular weight polymer; No residue; Fracturing fluid

\section{Introduction}

Wuliyasitai oilfield administrative is part of the Inner Mongolia Autonomous Region and there is $7 \mathrm{~km}$ to the north of Xilin Gol League Dongwuzhumuqinqi. Its construction belongs to the erlian basin depression northeast side mani. North east to strip type distribution on the whole, Area of $3000 \mathrm{~km} 2$, Reservoir porosity is $8 \% \sim 10 \%$ on average, Permeability is $0.05 \times 10-3 \sim 1.03$ $\mathrm{x}$ 10-3 um2. Belongs to low porosity and low permeability reservoirs, At the same time have the feature such as water sensitivity and alkali sensitivity. Fracturing usually use gel fracturing fluid, But due to its basic crosslinking environment and the characteristics of large residue content. The damage of alkali sensitivity reservoir is bigger. Synthetic polymer has always been the research object of water-based fracturing fluid because of neutral, good solubility, no residue, etc. It is also the ideal substitutes of melon gel fracturing fluid, But due to the time of crosslinking polymer fracturing fluid is fast, not easy to control, not resistant to shear, Defects and poor heat resistance make the application very restricted. Experimental study of low molecular weight polymer fracturing fluid - hydrophobic low molecular weight polymer as the main association of the new residue-free fracturing fluid system, solve the above problems. Low molecular weight polymer fracturing fluid is the use of special synthetic polymerization process, it has plurality of nodes of low molecular weight active high active lowmolecular polymer three yuan. Its molecular weight of 200,000 to 300,000 , Only about $1 / 10$ of a molecular weight of guar gum. It crosslinked under acidic conditions, and it has a strong tendency to selfpolymerization association between molecules. In the high temperature polymer to form a similar spatial network structure by coupling side chain. While the rigidity characteristic side chain groups covalently effect multicore inside the bridging hydroxyl ion reduction, crosslinking increases steric hindrance, Gel formation with temperature, shear resistance and good features. In this paper, preferably a low, medium, high temperature

\footnotetext{
${ }^{\mathrm{a}}$ Corresponding author: 155064851@qq.com
}

and low molecular weight polymer fracturing fluid formulation series, And achieved good effect in Wuliyasitai Oilfield, Ordos Basin Yishan slope of oil and gas wells fracturing.

\section{Low molecular weight polymer fracturing fluid laboratory study}

\subsection{Experimental part}

Chemical reagents and materials including the preparation of fracturing fluid thickener SD-3, organic titanium cross-linking agent, ammonium persulfate breaker, cleanup additive BSA-101, anti-swelling clay stabilizer BYH-8. Natural core were taken from 53 wells, 29 wells too, yan 620 wells.

Test instruments including MARS rheometer, K12 automatic table interfacial tension instrument, XB220A electronic balance, 30 to 70 high-speed mixing device, CL10 high-speed centrifuge, BINDER heated blast drying box, High temperature and high pressure core flow meter.

Fracturing fluid formulation: Adding a certain amount of water in the 30-70 high-speed mixing vessel, adding a certain amount of polymer SD-3 under stirring, Preparation of the required experimental fracturing fluid.

Fracturing fluid temperature shear resistance properties, gel breaking performance, the content of the residue was determined and the extent of fracturing fluid core damage evaluation: The method according to the oil and gas industry standards SY / T 5107-2005 "waterbased fracturing fluid performance evaluation methods" provisions.

Anti-expansion properties of fracturing fluid measurement: Based oil and gas industry standards SY/T5762-1995 method "Fracturing clay stabilizer performance measurement method" provisions.

\subsection{Results and discussion}




\subsubsection{Determination of water solubility and thickening properties}

Put $0.5 \%$ low molecular thickener SD - 3in $400 \mathrm{ml}$ water, Stirring was continued at room temperature for $25{ }^{\circ} \mathrm{C}, 300 \mathrm{r} / \mathrm{min}$ Condition, With six speed rotary viscosimeter test sol viscosity of the liquid in different time. The results showed that: Stir the $15 \mathrm{~min}$, Viscosity can be up to $91.1 \%$ of the final viscosity. Low molecular weight polymer water soluble speed, liquor easily at the scene.

Table 1. The relation between low molecular weight polymer fracturing fluid viscosity of sol solution and stirring time.

\begin{tabular}{|c|c|c|c|c|c|}
\hline $\begin{array}{c}\text { Time } \\
\text { min })\end{array}$ & 5 & 10 & 15 & 20 & 30 \\
\hline $\begin{array}{c}\text { Viscosit } \\
\text { mpa•s })\end{array}$ & 19.3 & 26.5 & 33.8 & 35.6 & 37.1 \\
\hline
\end{tabular}

When the room temperature is $25^{\circ} \mathrm{C}$, With water make different concentrations of low molecular weight polymer fracturing fluid, Under the condition of the speed of 300 r/min stir $15 \mathrm{~min}$. Standing swelling $1 \mathrm{~h}$, Use six speed rotating measuring sol viscosity fluid viscosity.The results showed that: Low molecular weight polymer to the thickening ability of water, The concentration of $0.2 \%$ $\sim 0.6 \%$ of the fracturing fluid can satisfy the requirement of fracturing operation.

Table 2. The relationship of Low molecular weight polymer fracturing fluid viscosity of sol solution and the concentration.

\begin{tabular}{ccccccc}
\hline $\begin{array}{c}\text { Concentration } \\
(\%)\end{array}$ & 0.2 & 0.3 & 0.4 & 0.5 & 0.6 & 1.0 \\
$\begin{array}{c}\text { Viscosit } \\
(\mathrm{mpa} \cdot \mathrm{s})\end{array}$ & 16.8 & 22.5 & 27.3 & 32.6 & 40.5 & 68.2 \\
\hline
\end{tabular}

\subsubsection{Crosslinking performance}

According to the SD - 3 molecules contain -CONH2 and -COO- perssad, it can be crosslinked by aldehyde, dialdehyde, six methylene tetramine and polyvalent metal ion $\mathrm{Al}^{3+}, \mathrm{Cr}^{3+}, \mathrm{Zr}^{4+}, \mathrm{Ti}^{4+}$. But research shows that a kind of crosslinking agent to form gel performance is not ideal, optimizing the organic zirconium and aldehyde compounds as crosslinking agent. The $\mathrm{pH}$ value of base fluid has a big influence on the crosslinking fracturing fluid properties and heat resistance performance. When the $\mathrm{pH}$ of base fluid within the scope of 5.5 to 6.2 , The fracturing fluid not only has a certain delay crosslinking, but also has good heat resistance performance. The experimental data are shown in table 3 .

Table 3. The effect of $\mathrm{PH}$ value on the cross-linking properties and heat resistance of the fracturing fluid

\begin{tabular}{|c|c|c|c|}
\hline $\begin{array}{c}\text { Regulators } \\
(\%)\end{array}$ & $\mathrm{pH}$ & $\begin{array}{c}\text { Crosslinking } \\
\text { time }(\mathrm{s})\end{array}$ & $\begin{array}{c}\mathrm{AV} 105^{\circ} \mathrm{C} \\
(\mathrm{mpa} \cdot \mathrm{s})\end{array}$ \\
\hline 0.5 & 6.5 & $15 \sim 25$ & 357 \\
\hline 0.6 & 6.2 & $30 \sim 40$ & 320 \\
\hline 0.7 & 6.0 & $40 \sim 50$ & 305 \\
\hline 0.8 & 5.7 & $60 \sim 80$ & 284 \\
\hline 0.9 & 5.5 & $90 \sim 120$ & 243 \\
\hline
\end{tabular}

\begin{tabular}{|l|l|c|c|}
\hline 1.0 & 5.2 & $250 \sim 320$ & 115 \\
\hline 1.1 & 5.0 & Uncrosslinked & \\
\hline
\end{tabular}

\subsubsection{Temperature resistance to shear performance}

Low molecular weight polymer fracturing fluid has good heat resistance shear resistance, Continuous shear 90 min under $105{ }^{\circ} \mathrm{C} 、 170 \mathrm{~s}-1$, Viscosity retention value is still high (greater than $100 \mathrm{mPa} \cdot \mathrm{s}$ ) , It shows that this fracturing fluid shear resistance of heat-resistant performance is good, it can meet fracturing created fracture and proppant requirements. The results shown in Figure 1.

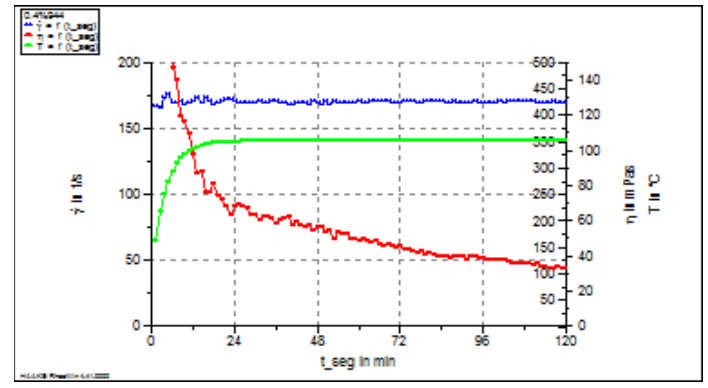

Figure 1. The rheological curve of $0.5 \%$ low molecular

weight polymer fracturing fluid when $105{ }^{\circ} \mathrm{C}, 170 \mathrm{~s}-1$

\subsubsection{Gel breaking performance}

The residue generated after gel breaking of gel fracturing fluid, it is difficult to discharge from the fracture, which will greatly reduce the fracture conductivity, and cause permanent damage to the formation. In order to reduce the formation fracturing and fracture conductivity damage, fracturing fluid gel breaking should as thoroughly as possible. And residue content in the gel breaking liquid should less as far as possible. Low molecular weight polymer fracturing fluid using oxidant ammonium persulfate gel water, Measured the gel breaking liquid viscosity of $0.5 \%$ low molecular weight polymer fracturing fluid were $3.5,20.4 \mathrm{mPa} \cdot \mathrm{s}$. which use $0.03 \%$ ammonium persulfate solution respectively, $0.03 \%$ ammonium persulfate solution + reacted acid as gel breaker. Under the experimental conditions, $0.03 \%$ ammonium persulfate and residual acid $(\mathrm{pH}>4)$ can make $0.5 \%$ low molecular weight polymer fracturing fluid gel breaking completely. Gel breaking liquid viscosity meet the provisions of the viscosity is not more than $5 \mathrm{mPa} \cdot \mathrm{s}$ requirement in SY/T 5674-2007 《General technical conditions for fracturing with plant gum $》$.

\subsubsection{Performance Evaluation of core damage}

Carried out a core damage experiment of tai 53 Wells and 29 well, yan 620 well with different fracturing fluid, The results showed that: Low molecular weight polymer fracturing fluid for core damage rate is less than $20 \%$, Guar gum fracturing fluid for core damage greater than $40 \%$, As shown in Table 4. 
Table 4. Different fracturing fluid on the rate of core damage

\begin{tabular}{|c|c|c|c|c|}
\hline $\begin{array}{c}\text { Core } \\
\text { Well } \\
\text { No. }\end{array}$ & $\begin{array}{c}\text { Fracturing fluid } \\
\text { types }\end{array}$ & $\begin{array}{c}\mathrm{K}_{0} / \\
10^{-3} \mu \mathrm{m}^{2}\end{array}$ & $\begin{array}{c}\mathrm{K}_{\mathrm{d}} / \\
10^{-3} \mu \mathrm{m}^{2}\end{array}$ & $\begin{array}{c}\text { Damage } \\
\text { rate } / \\
\%\end{array}$ \\
\hline $\begin{array}{c}\text { Tai } \\
53\end{array}$ & $\begin{array}{c}\text { Hydroxypropyl } \\
\text { guanidine gum }\end{array}$ & 0.268 & 0.224 & 16.4 \\
\cline { 2 - 5 } & $\begin{array}{c}\text { Low molecular } \\
\text { weight polymer }\end{array}$ & 0.283 & 0.166 & 41.5 \\
\hline \multirow{2}{*}{ Tai } \\
29 & $\begin{array}{c}\text { Hydroxypropyl } \\
\text { guanidine gum }\end{array}$ & 0.362 & 0.313 & 13.6 \\
\cline { 2 - 5 } & $\begin{array}{c}\text { Low molecular } \\
\text { weight polymer }\end{array}$ & 0.359 & 0.208 & 42.2 \\
\hline \multirow{2}{*}{$\begin{array}{c}\text { Yan } \\
620\end{array}$} & $\begin{array}{c}\text { Hydroxypropyl } \\
\text { guanidine gum }\end{array}$ & 0.210 & 0.178 & 15.3 \\
\cline { 2 - 5 } & $\begin{array}{c}\text { Low molecular } \\
\text { weight polymer }\end{array}$ & 0.198 & 0.118 & 40.6 \\
\hline
\end{tabular}

\begin{tabular}{|c|c|c|c|}
\hline $\mathrm{t}_{\text {Crosslinked }} / \mathrm{min}$ & $\begin{array}{c}\text { normal } \\
\text { temperature }\end{array}$ & $3 \sim 5$ & 4 \\
\hline $\begin{array}{c}\text { Gel breaking } \\
\text { liquid surface } \\
\text { tension / } \\
(\mathrm{mN} / \mathrm{m})\end{array}$ & $\begin{array}{c}\text { normal } \\
\text { temperature }\end{array}$ & $\leqslant 32.0$ & 30.0 \\
\hline $\begin{array}{c}\text { Gel breaking } \\
\text { liquid } \\
\text { interfacial } \\
\text { tension } / \\
(\mathrm{mN} / \mathrm{m})\end{array}$ & $\begin{array}{c}\text { normal } \\
\text { temperature }\end{array}$ & $\leqslant 5.0$ & 4.0 \\
\hline $\begin{array}{c}\text { Residue } \\
\text { content } / \mathrm{mg} / \mathrm{L}\end{array}$ & $\begin{array}{c}\text { normal } \\
\text { temperature }\end{array}$ & $\leqslant 600$ & 50 \\
\hline $\begin{array}{c}\text { Demulsificati } \\
\text { on rate } / \%\end{array}$ & $90^{\circ} \mathrm{C}$ & $\geq 95.0$ & 94.7 \\
\hline
\end{tabular}

\subsubsection{Comprehensive performance}

The comprehensive performance of low molecular weight polymer fracturing fluid shown in table 5.

Table 5. Polymer fracturing fluid routine performance

\begin{tabular}{|c|c|c|c|}
\hline Items & Conditions & $\begin{array}{c}\text { Reference } \\
\text { index }(0.5 \% \\
\text { Melon glue })\end{array}$ & Test results \\
\hline Apparent & $\begin{array}{c}\text { normal } \\
\text { temperature }\end{array}$ & $\begin{array}{c}\text { Without } \\
\text { delamination, } \\
\text { floc and } \\
\text { floats }\end{array}$ & $\begin{array}{c}\text { Without } \\
\text { delaminatio } \\
\mathrm{n} \text {, floc and } \\
\text { floats }\end{array}$ \\
\hline$\rho /\left(\mathrm{g} / \mathrm{cm}^{3}\right)$ & $\begin{array}{c}\text { normal } \\
\text { temperature }\end{array}$ & $1.00 \sim 1.02$ & 1.01 \\
\hline $\mathrm{PH}$ & $\begin{array}{c}\text { normal } \\
\text { temperature }\end{array}$ & $7 \sim 8$ & $6 \sim 7$ \\
\hline $\begin{array}{c}\mathrm{AV}_{\text {Base-fluid }} \\
/ \mathrm{mPa} \cdot \mathrm{s}\end{array}$ & $\begin{array}{c}\text { normal } \\
\text { temperature, } \\
170 \mathrm{~s}^{-1} \\
\text { swelling } 16 \mathrm{~h}\end{array}$ & 63 & 48 \\
\hline
\end{tabular}

\section{The field test and the analysis of the results}

In erlian basin wulisitai oilfield tai 27 wellblock use gum fracturing hydraulic fracture 4 Wells, The early daily oil production is $40.3 \mathrm{t}$, the average single well oil production is $10.08 \mathrm{t}$. Using low molecular weight polymer fracturing hydraulic fracture 4 Wells, The early daily oil production is $48.9 \mathrm{t}$, the average single well oil production is $12.23 \mathrm{t}$. The oil production increased by $21.3 \%$ than the melon gum fracturing fluid. In yishan slope of ordos basin using low molecular weight polymer fracturing hydraulic fracture 4 Wells, output has increased by 2 times above. Shown in table 6 . Using low molecular weight polymer fracturing hydraulic crack Y413 and Y620 gas Wells. Testing for production, Natural gas production were $1.2 \times 10^{4} \mathrm{~m}^{3}$ and $1.5 \times$ $10^{4} \mathrm{~m}^{3}$, The gas production increased by $25 \%$ than using hydroxypropyl melon gum fracturing hydraulic. Shown in table 7.

Table 6. Yishan slope well fracturing construction

\begin{tabular}{|c|c|c|c|c|c|c|c|c|}
\hline Well No. & $\begin{array}{c}\text { Fracturing } \\
\text { interval } / \mathrm{m}\end{array}$ & $\begin{array}{c}\text { Displacement } \\
/ \mathrm{m}^{3} / \mathrm{min}\end{array}$ & $\begin{array}{c}\text { Sand } \\
\text { ratio } \\
/ \%\end{array}$ & $\begin{array}{c}\text { Sand } \\
\text { proportion } \\
/ \mathrm{m}^{3}\end{array}$ & $\begin{array}{c}\text { Before fracturing } \\
\text { producing } \\
/ \mathrm{m}^{3} / \mathrm{d}\end{array}$ & $\begin{array}{c}\text { Oil } \\
\text { production } \\
/ \mathrm{t} / \mathrm{d}\end{array}$ & $\begin{array}{c}\text { Fluid } \\
\text { producing } \\
/ \mathrm{m}^{3} / \mathrm{d}\end{array}$ & $\begin{array}{c}\text { Oil } \\
\text { production } \\
/ \mathrm{t} / \mathrm{d}\end{array}$ \\
\hline $\mathrm{P} 3155-3$ & $\begin{array}{c}508.6 \sim \\
525.2\end{array}$ & $1.8 \sim 2.2$ & 26.3 & 20 & 2.46 & 0.81 & 6.75 & 2.96 \\
\hline $\mathrm{P} 2171-7$ & $\begin{array}{c}726.8 \sim \\
737.9\end{array}$ & $1.9 \sim 2.1$ & 27.6 & 16 & 1.69 & 0.59 & 5.86 & 2.85 \\
\hline P2181-5 & $\begin{array}{c}761.5 \sim \\
769.5\end{array}$ & $1.5 \sim 1.8$ & 28.1 & 12 & 1.36 & 0.35 & 4.89 & 1.56 \\
\hline $\mathrm{P} 2834-4$ & $\begin{array}{c}738.6 \sim \\
741.8\end{array}$ & $2.1 \sim 2.3$ & 26.6 & 19 & 2.85 & 0.68 & 7.16 & 2.81 \\
\hline
\end{tabular}

Note: Construction pressures of P3155-3、P2171-7、P2181-5 and C2834-4 well is 18 21、19 25、17 22 and 23 26 MPa.

Table 7. Gas well fracturing operation table

\begin{tabular}{|c|c|c|c|c|c|c|c|}
\hline $\begin{array}{l}\text { Well } \\
\text { No. }\end{array}$ & Perforation interval & $\begin{array}{l}\text { Displacement } \\
/ \mathrm{m}^{3} / \mathrm{min}\end{array}$ & $\begin{array}{c}\text { Construction } \\
/ \mathrm{MPa}\end{array}$ & $\begin{array}{c}\text { Sand ratio } \\
\qquad \%\end{array}$ & $\begin{array}{c}\text { Sand } \\
\text { proportion } \\
/ \mathrm{m}^{3}\end{array}$ & Infusion $/ \mathrm{m}^{3}$ & $\begin{array}{c}\text { Flowback rate } \\
/ \%\end{array}$ \\
\hline Y413 & $3402 \sim 3408$ & $3.2 \sim 3.6$ & $41 \sim 47$ & 24.6 & 35.2 & 289 & 81.9 \\
\hline
\end{tabular}




\begin{tabular}{|c|c|c|c|c|c|c|}
\hline & $3379 \sim 3383$ & $3.2 \sim 3.6$ & $40 \sim 46$ & 23.9 & 20.1 & 185 \\
\cline { 1 - 6 } Y620 & $3211 \sim 3215$ & $3.3 \sim 3.5$ & $43 \sim 49$ & 24.5 & 35.0 & 293 \\
\cline { 2 - 7 } & $3222 \sim 3225$ & 81.3 & \\
\hline
\end{tabular}

\section{Conclusion}

(1) The SD-3 low molecular weight polymer thickener has good solubility in water and salt resistance, the thickening ability and the advantages of no residue, can form crosslinked gel under neutral acidic conditions.

(2) The low molecular weight polymer fracturing fluid system has characteristics of high viscosity, seam and carrying capacity is strong, good heat resistance and shear resistance, to support cracks and low formation damage, etc, able to meet the needs of low permeability, alkali-sensitive and water-sensitive reservoir fracturing.

(3) The fracturing fluid composition simple, easy to configure and easy application.

\section{References}

1. Zhou cheng-yu, Chen fu, Huang lei, et. Development of a high temperature polymer fracturing fluid shear [J]. Drilling and completion fluid, 2008, 25(1): 67-72.

2. Yang zhen-zhou, Chen mian, Xu yun, et. New synthetic polymer ultra-high temperature fracturing fluid system $[\mathrm{J}]$. Drilling and completion fluid, 2011, 28(1): 49-5.

3. Lin bo, Liu tong-yi, Zhao zong-cong, et. Research and application of high-temperature fracturing fluid residue-free $[\mathrm{J}]$. Drilling and completion fluid, 2012, 29(5): 70-73. 